\title{
Mortality Following Clostridioides difficile Infection in Europe: A Retrospective Multicenter Case-Control Study
}

\author{
Jacek Czepiel 1,*(1), Marcela Krutova 2,3 , Assaf Mizrahi ${ }^{3,4,5}$ (), Nagham Khanafer ${ }^{3,6,7}$, David A. Enoch ${ }^{8}$,

 \\ Małgorzata Wójcik-Bugajska ${ }^{14}$, Iwona Filipczak-Bryniarska ${ }^{15}$, Bartosz Brzozowski ${ }^{16}$, Marcin Krzanowski ${ }^{17}$, \\ Katarzyna Konturek ${ }^{18}$, Marcin Fedewicz ${ }^{19}$, Mateusz Michalak ${ }^{20}$, Lorra Monpierre ${ }^{4}$, Philippe Vanhems ${ }^{6,7}$, \\ Theodore Gouliouris ${ }^{8}$, Artur Jurczyszyn ${ }^{21}$, Sarah Goldman-Mazur ${ }^{21}$, Dorota Wultańska ${ }^{13}$, Ed J. Kuijper ${ }^{3,22,23}$, \\ Jan Skupień ${ }^{24}$, Grażyna Biesiada ${ }^{1}$ and Aleksander Garlicki ${ }^{1}$
}

check for updates

Citation: Czepiel, J.; Krutova, M.; Mizrahi, A.; Khanafer, N.; Enoch,

D.A.; Patyi, M.; Deptuła, A.; Agodi,

A.; Nuvials, X.; Pituch, H.; et al.

Mortality Following Clostridioides difficile Infection in Europe: A Retrospective Multicenter Case-Control Study. Antibiotics 2021, 10, 299. https://doi.org/10.3390/ antibiotics10030299

Academic Editor: Guido Granata

Received: 15 February 2021

Accepted: 10 March 2021

Published: 13 March 2021

Publisher's Note: MDPI stays neutral with regard to jurisdictional claims in published maps and institutional affiliations.

Copyright: (c) 2021 by the authors. Licensee MDPI, Basel, Switzerland. This article is an open access article distributed under the terms and conditions of the Creative Commons Attribution (CC BY) license (https:/ / creativecommons.org/licenses/by/ $4.0 /)$.
1 Department of Infectious and Tropical Diseases, Jagiellonian University Medical College, 30-688 Krakow, Poland; gbiesiada@op.pl (G.B.); agarlicki@gmail.com (A.G.)

2 Department of Medical Microbiology, Charles University, 2nd Faculty of Medicine and Motol University Hospital, 15006 Prague, Czech Republic; marcela.krutova@lfmotol.cuni.cz or marcela.krutova@seznam.cz

3 ESCMID Study Group for Clostridioides Difficile (ESGCD), 4001 Basel, Switzerland; amizrahi@hpsj.fr (A.M.); nagham.khanafer@chu-lyon.fr (N.K.); hanna.pituch@wum.edu.pl (H.P.); e.j.kuijper@lumc.nl (E.J.K.)

4 Service de Microbiologie Clinique, Groupe Hospitalier Paris Saint-Joseph, 75014 Paris, France; lorra.monpierre@hotmail.fr

5 Institut Micalis UMR 1319, Université Paris-Saclay, INRAe, AgroParisTech, 92290 Châtenay Malabry, France

6 Unité d'Hygiène, Epidémiologie et Prévention, Groupement Hospitalier Centre, Hospices Civils de Lyon, 69002 Lyon, France; philippe.vanhems@chu-lyon.fr

7 Centre International de Recherche en Infectiologie (CIRI), Public Health, Epidemiology and Evolutionary Ecology of Infectious Diseases (PHE3ID), Université de Lyon, 69372 Lyon, France

8 Clinical Microbiology \& Public Health Laboratory, Public Health England, Addenbrooke's Hospital, Hills Road, Cambridge CB2 0QQ, UK; david.enoch@addenbrookes.nhs.uk (D.A.E.); theodore.gouliouris@addenbrookes.nhs.uk (T.G.)

9 Hygienic Department, Bács-Kiskun County Teaching Hospital, 6000 Bács-Kiskun, Hungary; patyim@kmk.hu

10 Department of Propaedeutics of Medicine and Infection Prevention, Ludwik Rydygier Collegium Medicum in Bydgoszcz, Nicolaus Copernicus University, 85-094 Bydgoszcz, Poland; deptula.aleksander@gmail.com

11 Department of Medical and Surgical Sciences and Advanced Technologies "GF Ingrassia", University of Catania, 95123 Catania, Italy; agodia@unict.it

12 Critical Care Department, Vall d'Hebron Hospital, Vall d'Hebron Institut de Recerca (VHIR), SODIR Group, Universitat Autònoma de Barcelona, 08035 Barcelona, Spain; fxnuvials@vhebron.net

13 Department of Medical Microbiology, Medical University of Warsaw, 02-004 Warsaw, Poland; dorota.wultanska@wum.edu.pl

14 Department of Internal and Geriatric Diseases, Jagiellonian University Medical College, 30-688 Krakow, Poland; mwojcik@su.krakow.pl

15 Department of Pain Treatment and Palliative Care, Jagiellonian University Medical College, 30-688 Krakow, Poland; inusia_bryniarska@yahoo.pl

16 Department of Gastroenterology and Hepatology, Jagiellonian University Medical College, 30-688 Krakow, Poland; bartek.brzozowski@op.pl

17 Department of Nephrology and Dialysis Unit, Jagiellonian University Medical College, 30-688 Krakow, Poland; mkrzanowski@op.pl

18 Intensive Care Unit, University Hospital, 30-688 Krakow, Poland; kliber@su.krakow.pl

19 Józef Babiński Hospital, 30-393 Krakow, Poland; marcin.fedewicz@gmail.com

20 Ludwik Rydygier Hospital, 31-826 Krakow, Poland; michalakcontact@gmail.com

21 Department of Hematology, Jagiellonian University Medical College, 30-688 Krakow, Poland; mmjurczy@cyf-kr.edu.pl (A.J.); senoritagoldman@gmail.com (S.G.M.)

22 Department of Medical Microbiology, Centre for Infectious Diseases, Leiden University Medical Center, 2333 Leiden, The Netherlands

23 Centre for Infectious Diseases Research, Diagnostics and Laboratory, Surveillance, Rijksinstituut voor Volksgezondheid en Milieu, 2333 Bilthoven, The Netherlands

24 Department of Metabolic Diseases, Jagiellonian University Medical College, 30-688 Krakow, Poland; jan.skupien@gmail.com

* Correspondence: jacek.czepiel@uj.edu.pl; Tel./Fax: +48-124002022/17 


\begin{abstract}
We aimed to describe the clinical presentation, treatment, outcome and report on factors associated with mortality over a 90-day period in Clostridioides difficile infection (CDI). Descriptive, univariate, and multivariate regression analyses were performed on data collected in a retrospective case-control study conducted in nine hospitals from seven European countries. A total of 624 patients were included, of which 415 were deceased (cases) and 209 were still alive 90 days after a CDI diagnosis (controls). The most common antibiotics used previously in both groups were $\beta$-lactams; previous exposure to fluoroquinolones was significantly $(p=0.0004)$ greater in deceased patients. Multivariate logistic regression showed that the factors independently related with death during CDI were older age, inadequate CDI therapy, cachexia, malignancy, Charlson Index, long-term care, elevated white blood cell count (WBC), C-reactive protein (CRP), bacteraemia, complications, and cognitive impairment. In addition, older age, higher levels of WBC, neutrophil, CRP or creatinine, the presence of malignancy, cognitive impairment, and complications were strongly correlated with shortening the time from CDI diagnosis to death. CDI prevention should be primarily focused on hospitalised elderly people receiving antibiotics. WBC, neutrophil count, CRP, creatinine, albumin and lactate levels should be tested in every hospitalised patient treated for CDI to assess the risk of a fatal outcome.
\end{abstract}

Keywords: Clostridioides difficile infection; co-morbidities; mortality; malignancy; outcome; risk factors

\title{
1. Introduction
}

Clostridioides difficile (C. difficile), formerly known as Clostridium difficile, is the most common cause of healthcare-associated infectious diarrhoea in the developed world. The incidence and severity of $C$. difficile infections (CDI) have risen in recent years with a considerable impact in terms of morbidity, mortality, and financial cost [1]. The burden of healthcare-associated CDIs in acute care hospitals in the European Economic Area was estimated at 123,997 cases annually [2]. In the United States, C. difficile is the most common cause of healthcare-associated infections, accounting for approximately $15 \%$ of them [3]. According to data from 2012, C. difficile caused approximately half a million infections and 29,000 deaths in the US [4]. The pooled incidence rate of CDI in Asia was calculated by meta-analysis at 5.3/10,000 patient days (95\% CI 4.0-6.7) [5].

Increasing antibiotic use, improved life expectancy, increasing numbers of at-risk patients and the emergence of hypervirulent epidemic strains (e.g., ribotype PCR 027) may explain the increased incidence of CDI and these factors, in addition to hospitalisation, are key factors in the development of CDI [6,7]. Inflammatory bowel disease, gastrointestinal surgery, and conditions impairing the immune system (e.g., malignant neoplasms, transplantation, chronic kidney disease, and immunosuppressant use) also predispose towards CDI $[8,9]$. The clinical spectrum of CDI varies in severity from asymptomatic carriage and self-limited, mild diarrhoea to severe colitis, intestinal perforation, toxic megacolon, and death $[7,10]$. Mortality rates in CDI vary widely between studies. Before 2000, mortality associated with CDI was $<2 \%$, whereas mortality in studies since 2000 averaged $5 \%$ in endemic case and $7-17 \%$ in epidemic cases [11-15]. The mortality has been twice as high in Intensive Care Unit (ICU) patients with CDI compared to ICU patients without CDI [16,17].

We aimed to describe the risk factors, clinical presentation, and management of patients with CDI as well as reported factors associated with mortality in the 90-day period after diagnosis.

\section{Materials and Methods}

\subsection{Study Population}

Using the European Society of Clinical Microbiology and Infectious Diseases (ESCMID) Study Group for C. difficile members, 17 hospitals were selected for this study. Nine hospitals from seven European countries (Czech Republic, France, Hungary, Italy, Poland, Spain, and United Kingdom) participated in this retrospective case-control study. 
Patients hospitalised between January 2011 and December 2019 with a diagnosis of CDI who died within 90 days following a CDI diagnosis formed the case group that was compared in a 2:1 ratio to a group of control patients with a CDI diagnosis hospitalised in the same wards over the same time period who survived.

\subsection{Data Collection}

Electronic hospital databases were used to collect patient data on: sex, age, body mass index (BMI), prior hospitalisations, dwelling in a long-term care (LTC) facility, recent surgery, parenteral nutrition, previous use (in last 3 months) of antibiotics, probiotics, proton pump inhibitors (PPIs), $\mathrm{H} 2$ blockers (H2b), immunosuppressants (defined as agents that can suppress or prevent the immune response), information on comorbidities needed to calculate the Charlson Index and dates of admission, CDI diagnosis, and deaths. The following data on the CDI episode were gathered: episode number, blood parameters at the time of diagnosis [white blood cell count (WBC), neutrophil count, C-reactive protein (CRP), creatinine, albumin, and lactate levels], associated bacteraemia, imaging procedures performed (abdominal ultrasound, computed tomography), colonoscopy and CDI therapy, as well as outcomes and complications (i.e., failure of any organ, infection, ileus, colon perforation, toxic megacolon, and bleeding from the digestive tract).

\subsection{Definitions}

A CDI case was defined as a patient with the symptoms of CDI and positive laboratory test(s) according to ESCMID guidelines [18]. Healthcare-associated CDI (HA-CDI) was defined as a patient who developed the symptoms of CDI in a healthcare facility on day three or later, following admission to a healthcare facility on day one, or who had onset in the community within four weeks after being discharged from a healthcare facility. Community-associated CDI (CA-CDI) was defined as a patient who had the onset of symptoms either outside of the healthcare facilities, or whose symptoms appeared in a healthcare facility within $48 \mathrm{~h}$ after admission but who had not been discharged from a healthcare facility within a 12 week period prior to the onset of symptoms [19]. Cases that did not fit any of these criteria were classified as unknown.

\subsection{Statistical Analysis}

For descriptive purposes continuous variables are presented as medians, lower (1 st) and upper ( $3 \mathrm{rd}$ ) quartiles. Categorical variables are presented as counts and percentages. Summary statistics were computed for the group of deceased patients and the control group of patients, who recovered from CDI. The frequencies of categorical variables were compared with the $\chi^{2}$ test or Fisher's exact test, where applicable. Spearman correlation coefficients with appropriate asymptotic tests were calculated for select continuous variables and time to death. For categorical variables (including binary and ordinal ones), we used Kendall's correlation. To identify a set of statistically independent predictors of CDI mortality, we used logistic regression models. Variable selection was performed using the LASSO (least absolute shrinkage and selection operator) method with 10-fold cross-validation. A one standard deviation rule was used to select a parsimonious set of candidate variables. In the final multivariate logistic model, we retained only statistically significant predictors, and their joint predictive performance was evaluated with C-statistic. $p$-values $<0.05$ were considered to be significant. Data processing and statistical calculations were performed with R 3.6.3 (The R Foundation for Statistical Computing, Vienna, Austria).

\section{Results}

\subsection{Descriptive Analysis of Included Patients}

Data were collected from 624 hospitalised patients with CDI; 415 patients died (cases) and 209 patients were still alive 90 days after a CDI diagnosis (controls). The gender distribution was similar in both groups but slightly skewed toward women, $(210 ; 51 \%$ in the deceased group), versus $118(57 \%)$ in the controls $(p=0.17)$. The median age was 80 years 
in the deceased group and 72 years in the control group $(p<0.001)$. People $\geq 65$ years-old constituted $86 \%(n=357)$ of the deceased group and $67 \%(n=140)$ in the control group $(p<0.001)$. People $\geq 80$ years-old constituted $50 \%(\mathrm{n}=208)$ of the deceased group and $28 \%(\mathrm{n}=59)$ in the control group $(p<0.001)$. The patients' median age in the deceased group was, on average, 8 years higher and their Charlson Index was twice as high as in the control group $(p<0.001)$. The comparison of data on previous hospitalisations, surgeries, LTC stays, parenteral nutrition, use of probiotics, PPI, and $\mathrm{H} 2 \mathrm{~b}$ between the two groups of patients are shown in Table 1.

Table 1. Comparison of demographic and clinical data in the study groups.

\begin{tabular}{|c|c|c|c|}
\hline \multirow[t]{2}{*}{ Characteristic } & $\begin{array}{l}\text { CDI-Deceased Group } \\
(\mathrm{N}=415)\end{array}$ & $\begin{array}{l}\text { CDI-Control Group } \\
(\mathrm{N}=\mathbf{2 0 9})\end{array}$ & \multirow[t]{2}{*}{$p$ Value } \\
\hline & N (\%) or Median (1st, 3rd Quartile) & N (\%) or Median (1st, 3rd Quartile) & \\
\hline Age (years) & $80(70,86)$ & $72(59,82)$ & $<0.0001$ \\
\hline Sex (male) & $205(49.4 \%)$ & $91(43.5 \%)$ & 0.17 \\
\hline $\operatorname{BMI}\left(\mathrm{kg} / \mathrm{m}^{2}\right) *$ & $24.2(21.1,27.7)$ & $25.0(22.1,27.8)$ & 0.39 \\
\hline Charlson Index & $4(3,6)$ & $2(1,4)$ & $<0.0001$ \\
\hline Previous hospitalisations & $313(75.4 \%)$ & $132(63.2 \%)$ & 0.001 \\
\hline Previous parenteral nutrition & $33(8.0 \%)$ & $17(8.1 \%)$ & 0.94 \\
\hline Previous surgery & $77(18.6 \%)$ & $47(22.5 \%)$ & 0.24 \\
\hline Previous LTC facility & $56(13.5 \%)$ & $10(4.8 \%)$ & 0.0008 \\
\hline Previous probiotics use & $61(14.7 \%)$ & $21(10.0 \%)$ & 0.11 \\
\hline Previous PPI use * & $219(56.4 \%)$ & $104(50.2 \%)$ & 0.15 \\
\hline Previous $\mathrm{H} 2 \mathrm{~b}$ use * & $22(5.3 \%)$ & $9(4.3 \%)$ & 0.59 \\
\hline
\end{tabular}

BMI, body mass index; CDI, Clostridioides difficile infection; H2b, H2 blockers; LTC, long term care; PPI proton pomp inhibitors. ${ }^{*}$ Missing data: BMI: 186 cases in the deceased group and 49 cases in the control group; PPI use: 27 cases in the deceased group and 2 cases in the control group; $\mathrm{H} 2 \mathrm{~b}$ use: 2 cases in the deceased group and 1 case in the control group.

The number of patients who had HA-CDI was $280(68 \%)$ among the deceased patients and $131(63 \%)$ in the control group with CA-CDI. Fourteen $(3 \%)$ in the deceased group and $20(10 \%)$ in the control group $(p=0.006)$ were classed as CA-CDI. The origin of the CDI was unknown in 121 patients (29\%) from the deceased group and in 58 patients (28\%) from the control group.

Table 2 lists the most commonly used antibiotics (or antibiotic class) in the preceding 3 months. The use of $\beta$-lactams was most prevalent in both groups. The administration of fluoroquinolones was more frequent in the deceased group than in the control group.

Table 2. Antibiotics used in the 3 months prior to the episode of CDI.

\begin{tabular}{cccc}
\hline Antibiotic & CDI-Deceased Group & CDI-Control Group & N (\%) \\
\hline No antibiotic & N (\%) & $25(12.0 \%)$ & $p$ Value \\
Fluoroquinolones & $35(8.4 \%)$ & $51(24.4 \%)$ & 0.16 \\
BLBLI & $160(38.6 \%)$ & $60(28.7 \%)$ & 0.0004 \\
Third generation cephalosporins & $152(36.6 \%)$ & $60(28.7 \%)$ & 0.049 \\
Carbapenems & $147(35.4 \%)$ & $31(14.8 \%)$ & 0.09 \\
Aminoglycosides & $68(16.4 \%)$ & $14(6.7 \%)$ & 0.62 \\
Metronidazole & $45(10.8 \%)$ & $27(12.9 \%)$ & 0.09 \\
\hline
\end{tabular}

BLBLI, $\beta$-lactam/ $\beta$-lactamase inhibitor; CDI, Clostridioides difficile infection; Some patients used more than one antibiotic, therefore the percentage sum does not equal $100 \%$.

The incidence of co-morbidities as possible risk factors for CDI mortality is shown in Table 3. At least one co-morbidity was recorded in $76 \%$ of patients in the deceased group and $53 \%$ in the control group $(p<0.001)$. In the deceased group, a malignancy was the most prevalent comorbidity. Diabetes, chronic kidney disease, cachexia, and liver cirrhosis were also more common in deceased patients compared to controls. 
Table 3. The frequency of co-morbidities regarded as possible risk factors for CDI mortality.

\begin{tabular}{cccc}
\hline Comorbidity & CDI-Deceased Group & CDI-Control Group & $p$ Value \\
N (\%) & N (\%) & $111(53.1 \%)$ & $<0.0001$ \\
\hline At least one comorbidity & $316(76.1 \%)$ & $40(19.1 \%)$ & $<0.0001$ \\
Malignancy & $155(37.3 \%)$ & $38(18.2 \%)$ & 0.004 \\
Diabetes mellitus & $120(28.9 \%)$ & $32(15.3 \%)$ & 0.001 \\
Chronic kidney disease & $112(27.0 \%)$ & $39(18.7 \%)$ & 0.74 \\
Immunosuppressive therapy & $73(17.6 \%)$ & $5(2.4 \%)$ & 0.0001 \\
Cachexia & $47(11.3 \%)$ & $6(2.9 \%)$ & 0.44 \\
Immunosuppressive disease & $17(4.1 \%)$ & $0(0 \%)$ & 0.004 \\
Liver cirrhosis & $14(3.4 \%)$ & $4(1.9 \%)$ & 0.49 \\
IBD & $5(1.2 \%)$ & \\
\hline
\end{tabular}

CDI, Clostridioides difficile infection; IBD, inflammatory bowel disease. Some patients had more than one factor, therefore the percentage sum does not always equal $100 \%$.

\subsection{The Clinical Course of CDI}

Data pertaining to the course of CDI are shown in Table 4. An increased WBC, neutrophils, CRP, creatinine, and lactate, and a lower serum albumin concentration were found to be significantly more frequent in patients with a fatal outcome of CDI compared to the control group. Complications during the course of CDI and cognitive impairment were more common in the deceased group compared to controls. The time between admission of patients and a CDI diagnosis was longer in the deceased group of patients compared to the controls.

Table 4. Data pertaining to the clinical course of CDI.

\begin{tabular}{|c|c|c|c|c|c|}
\hline \multirow[b]{2}{*}{ Characteristic } & \multicolumn{2}{|c|}{ CDI-Deceased Group } & \multicolumn{2}{|c|}{ CDI-Control Group } & \multirow[b]{2}{*}{$\begin{array}{c}p \\
\text { Value }\end{array}$} \\
\hline & $\begin{array}{c}\text { N (\%) } \\
\text { or Median (1st, 3rd Quartile) }\end{array}$ & N Missing & $\begin{array}{c}\text { N (\%) } \\
\text { or Median (1st, 3rd quartile) }\end{array}$ & N Missing & \\
\hline Body temperature $\left({ }^{\circ} \mathrm{C}\right)$ & $36.6(36.5,37.1)$ & 127 & $36.8(36.6,37.6)$ & 74 & 0.005 \\
\hline WBC count $(\times 1000 / \mu \mathrm{L})$ & $13.7(8.8,22.3)$ & 14 & $9.6(7.2,14.0)$ & 1 & $<0.0001$ \\
\hline Neutrophil count $(\times 1000 / \mu \mathrm{L})$ & $10.4(6.1,18.0)$ & 186 & $7.2(4.7,10.9)$ & 51 & $<0.0001$ \\
\hline $\mathrm{CRP}(\mathrm{mg} / \mathrm{L})$ & $116(70,198)$ & 67 & $65(23,120)$ & 17 & $<0.0001$ \\
\hline Serum creatinine $(\mu \mathrm{mol} / \mathrm{L})$ & $107(67,192)$ & 34 & $75(60,113)$ & 5 & $<0.0001$ \\
\hline Serum albumin $(\mathrm{g} / \mathrm{L})$ & $24(20,28)$ & 173 & $28(23,32)$ & 99 & $<0.0001$ \\
\hline Serum lactate (mmol/L) & $1,8(1.4,3.3)$ & 356 & $1.0(0.8,1.7)$ & 187 & 0.0002 \\
\hline Bacteremia & $45(10.8 \%)$ & 0 & $6(2.9 \%)$ & 0 & 0.0006 \\
\hline Episode number & & 0 & & 0 & 0.18 \\
\hline 1 & $365(88.0 \%)$ & & $177(84.7 \%)$ & & \\
\hline 2 & $41(9.9 \%)$ & & $22(10.5 \%)$ & & \\
\hline 3 & $6(1.4 \%)$ & 0 & $5(2.4 \%)$ & 0 & 0.18 \\
\hline 4 & $2(0.5 \%)$ & & $5(2.4 \%)$ & & \\
\hline 5 & $1(0.2 \%)$ & & $0(0 \%)$ & & \\
\hline Complications (without deaths) & $101(24.3 \%)$ & 0 & $21(10.0 \%)$ & 0 & $<0.0001$ \\
\hline Cognitive impairment & $92(22.2 \%)$ & 0 & $6(2.9 \%)$ & 0 & $<0.0001$ \\
\hline Surgery after CDI diagnosis & $10(2.4 \%)$ & 0 & $4(1.9 \%)$ & 0 & 0.78 \\
\hline Days from admission to diagnosis & $7(1,18)$ & 1 & $5(1,13)$ & 0 & 0.01 \\
\hline Days from diagnosis to death & $12(4,25)$ & 0 & NA & NA & NA \\
\hline
\end{tabular}

CDI, Clostridioides difficile infection; CRP, C-reactive protein; NA, not applicable; WBC, white blood cells.

Abdominal ultrasound was performed in 36 cases in the deceased group (9\%) and 37 cases $(18 \%)$ in the control group $(p<0.001)$. Findings of importance in CDI (ascites, thickening of the intestinal wall of the colon, and/or increase in the lumen diameter of the colon) were discovered in 29 cases (81\%) of the deceased group, compared to 14 (38\%) in tests performed on the control group $(p<0.001)$. CT imaging was performed in 54 cases in the deceased group (13\%) and in 15 cases in the control group (7\%), $p=0.03$. Important findings on CT (same as in ultrasonography) were discovered in $76 \%$ of procedures performed on the deceased group, compared to $67 \%$ in the control group $(p=0.51)$. Colonoscopy was performed on 7 patients in the deceased group $(1.7 \%)$ and on 5 patients in the control group $(2.4 \%), p=0.55$. 
Fourteen different CDI treatment regimens were employed in the deceased group and eight in the control group. The chosen therapy was changed due to side effects in 3 cases $(1 \%)$ in the deceased group, and in 3 cases $(1 \%)$ in controls. Oral metronidazole was the most common treatment in both groups, $n=179$, at $43 \%$ in the deceased group, and $n=100$, as well as $48 \%$ in the control group. This treatment was unchanged in 131 and 86 patients from the respective groups. Thirteen people (3.1\%) in the deceased group and 5 patients $(2.4 \%)$ in the control group did not receive any antibiotic treatment for CDI.

The most common complications in the deceased group were failure of at least one vital organ $(n=36 ; 9 \%)$, pneumonia $(n=32 ; 8 \%)$, and sepsis $(n=14 ; 3 \%)$. Blood cultures were positive in five patients in the deceased group; the confirmed pathogens were: Acinetobacter baumannii, Citrobacter koseri, Enterobacter cloacae, Candida albicans and a mixture from one patient (Staphylococcus epidermidis, Staphylococcus haemolyticus, and Enterococcus faecium). Complications involving the gastrointestinal tract included ileus $(\mathrm{n}=7 ; 2 \%)$, toxic megacolon $(n=3 ; 1 \%)$, bleeding $(n=3 ; 1 \%)$, intestinal ischaemia $(n=2 ; 0.5 \%)$, and gastrointestinal perforation $(n=1 ; 0.2 \%)$. The most commonly occurring complications in the control group were secondary infections: pneumonia $(n=10 ; 5 \%)$, urinary tract infections $(n=6 ; 3 \%)$, and sepsis $(n=4 ; 2 \%)$.

\subsection{Predictors of Death in CDI}

Multivariate logistic regression identified 11 factors that together discriminated CDI deaths from controls. The most important were advanced age, the presence of malignancy, a higher Charlson Index, WBC (1000/ $\mu \mathrm{L}$ increase), CRP (100 mg/L increase), the presence of complications, and the presence of cognitive impairment (Table 5). The discriminative accuracy of this model was considerably high, as the C-statistic was 0.864 .

Table 5. List of independent death predictors in a multivariate logistic regression model.

\begin{tabular}{ccc}
\hline Covariate & Odds Ratio $\mathbf{9 5 \% \text { Confidence Interval) }}$ & $p$ Value \\
\hline Age (10-year increase) & $1.57(1.31,1.89)$ & $<0.001$ \\
inadequate antibiotics * & $3.70(1.08,12.69)$ & 0.04 \\
Cachexia & $5.00(1.34,18.57)$ & 0.02 \\
Malignancy & $2.62(1.43,4.81)$ & 0.002 \\
Charlson Index $(1$ unit increase) & $1.24(1.11,1.39)$ & 0.0001 \\
long term care & $2.42(1.05,5.58)$ & 0.04 \\
WBC (1000/ $\mu$ increase) & $1.03(1.01,1.06)$ & 0.005 \\
CRP (100 mg/l increase) & $1.80(1.34,2.43)$ & 0.0001 \\
Bacteremia & $3.35(1.06,9.93)$ & 0.04 \\
Complications (without deaths) & $3.95(2.08,7.50)$ & $<0.001$ \\
Cognitive impairment & $7.50(2.73,20.66)$ & $<0.001$
\end{tabular}

Model C-statistic $=0.864 ;$ CRP C-reactive protein; $\mathrm{WBC}$ white blood cell; ${ }^{*}$ - use of ineffective treatment such as intravenous metronidazole or vancomycin in monotherapy, or ineffective antibiotics, such as tigecycline.

Correlation was assessed between selected parameters and the time from CDI diagnosis to death. Advanced age, higher levels of WBC, neutrophil, CRP or creatinine, the presence of malignancy, cognitive impairment, and complications were strongly correlated with hastening death (Table 6).

Table 6. Spearman or Kendall (for categorical, binary or ordinal variables) correlations between select characteristics and days from CDI diagnosis to death.

\begin{tabular}{ccc}
\hline Variable & $\rho / \tau$ & $p$ Value \\
\hline Age & -0.15 & 0.0024 \\
Malignancy & 0.08 & 0.038 \\
WBC count & -0.17 & 0.0005 \\
\hline
\end{tabular}


Table 6. Cont.

\begin{tabular}{ccc}
\hline Variable & $\rho / \tau$ & $p$ Value \\
\hline Neutrophil count & -0.30 & $<0.0001$ \\
CRP & -0.27 & $<0.0001$ \\
Serum creatinine & -0.18 & 0.0005 \\
Complications (without deaths) & 0.11 & 0.0093 \\
Cognitive impairment & -0.14 & 0.0008 \\
\hline
\end{tabular}

CRP C-reactive protein; WBC white blood cell, included only variables with $p<0.05$.

Research data are available as Supplementary Materials.

\section{Discussion}

To the best of our knowledge, this study is the largest analysis of patients with a fatal outcome of CDI in multiple sites across Europe.

We confirm that increasing age is an important risk factor for a fatal outcome of CDI, as described previously $[20,21]$. A systematic review which included 30 studies showed that increasing age is among the most reported risk factor for mortality in patients with CDI [22]. This is most likely due to the weaker immune response to the $C$. difficile toxin. Moreover, the elderly are characterized by a greater number of chronic diseases, including those that contribute to a worse course of CDI, such as chronic kidney disease, diabetes, or malignancy [23]. Gender is not an important factor since the risk was similar for both males and females, as described in other studies [21,24,25].

The presence of any comorbidity $(p<0.0001)$ and increasing Charlson Index $(p=<0.0001)$ were also associated with increased mortality. This has been described elsewhere $[20,21,26]$, but some studies did not confirm such observations [27]. This may be the result of the different characteristics of the population or study design. Oncology patients face a number of risk factors that are predisposed to CDI acquisition, including frequent and prolonged hospitalisations, increased antibiotic use (both prophylactic and therapeutic), and chemotherapy [28]. We found malignancy to be an independent factor of mortality risk. The pathogenesis of CDI, during and after chemotherapy, is not yet fully understood but suggestions include a negative impact on the gastrointestinal microbiota, direct damage to intestinal mucosa, and immunological mechanisms in the neoplastic process predisposing to CDI [29-31]. In a large analysis of outcomes of 30,000 patients with cancer, those with CDI had a significantly higher mortality rate $(9.4 \%$ vs. $7.5 \%, p<0.0001)$ [32]. Among other comorbidities, liver cirrhosis and cachexia were more prevalent in the deceased group but only cachexia was independent death risk predictor. Patients with liver cirrhosis and cachexia are typically characterised by low levels of albumin, a recognised risk factor for severe CDI [7], and in our study, low albumin levels were strongly correlated with the risk of death. Surprisingly IBD was not related with 90-days mortality; however, the total number of patients with IBD in both groups was low. IBD is a known risk factor both for development of CDI and mortality [24,33]. We also noted an association with chronic kidney disease and increased mortality which has also been reported previously, particularly in patients with end-stage renal disease and patients on dialysis, compared to the general population [34,35]. Diabetes is also a predisposing factor for CDI development and recurrence [36,37], but it was not shown to be a mortality-related factor $[20,25,27]$. In our study diabetes was more prevalent in the deceased group, but it was not independent death predictor, when assessed in the multivariate logistic regression model.

CDI is a recognised problem in LTC facilities; residents are often elderly with multiple co-morbidities. LTC admission 90 days before CDI was related with 30-day all-cause mortality in one study [27]. We also found that previous LTC residency was more prevalent in the deceased group and was independently associated with a fatal outcome.

It is suggested that a patients' weight has an impact on outcome from CDI. One study suggested that being underweight $(\mathrm{BMI}<19)$ or morbidly obese $(\mathrm{BMI}>40)$ was associated with an increased in-hospital mortality in patients with CDI [38], while another reported that underweight patients with CDI are at higher risk of poor outcome than 
normal, overweight, and obese patients [39]. Therefore, one of our aims was to establish if there was any association between a patient's BMI and its impact on the course of CDI. Calculating BMI sometimes poses a challenge, since the most severely ill, often bedridden patients cannot be weighed properly. BMI data were only available in $55 \%$ of our cases; however, considering the large population of patients in our study, their number was sufficient to conclude that BMI did not increase mortality in CDI.

Previous hospitalisation was more prevalent in the deceased group but was not independent risk factor of death, which confirmed the findings of Morrison et al. study [24].

In our study, the previous use of PPIs and/or H2b before a CDI episode was not associated with a fatal outcome; these findings are contrary to a study by Morrison et al. [24]. In another report, the use of PPIs, but not $\mathrm{H} 2 \mathrm{~b}$, was a predictor of mortality within 30 days after the end of treatment for a CDI recurrence; however, there are some differences in the methodology compared to our study [27].

Antibiotic use alters gut microbiota that physiologically protects the gastrointestinal tract from colonisation by pathogens, including $C$. difficile. In our study, we demonstrated that antibiotic treatment was the most common risk factor for CDI mortality (92\% in the deceased group and $88 \%$ in the control group). The most frequently used antimicrobials were $\beta$-lactams and fluoroquinolones, two of the " $4 C$ " antibiotics in which stewardship intervention can lead to a decline in prevalence of epidemic $C$. difficile ribotypes [40].

In our population of 624 study participants, every patient had at least one risk factor for the development of CDI. It is also notable that only 7 patients $(1.1 \%)$ did not have any of the 3 main CDI risk factors (age > 65; previous hospitalisation or antibiotic use). This is of importance, since it suggests that patients with no risk factors are less likely to develop CDI.

We analysed blood parameters which are known risk markers for poor outcomes in CDI [41-43]. These parameters are very useful in clinical practice, as they can be assessed cheaply, objectively, and early in the course of CDI. The differences in their values between both groups are pronounced. It is worth noting, however, that although the WBC count was almost always tested, this was not always the case for other parameters and the percentage of tests performed (creatinine, CRP, neutrophil count, albumin and lactate) was low. We found that WBC and neutrophil counts, CRP, and creatinine were strongly correlated with shortening the time from CDI diagnosis to death. Moreover, WBC and CRP were independent predictors of death.

In the deceased group, $88 \%$ of patients died during the first episode which is consistent with the notion that the highest risk of death is associated with the first episode of CDI [44]. Colonoscopies were rarely performed in our study. Endoscopic evaluation can be useful; however, it is indicated only if diagnostic problems occur, e.g., when an alternative diagnosis is suspected and direct visualisation and/or biopsy of the bowel mucosa is needed [7]. Computed tomography and ultrasounds are useful among patients with severe CDI helping to evaluate for presence of complications like toxic megacolon or bowel perforation [45]. The number of these examinations in our study was relatively small, and it is especially surprising that ultrasound examinations were performed much less frequently in the deceased group.

Oral metronidazole was the most frequently used drug in CDI treatment in our study. This is despite recent guidance suggesting vancomycin and/or fidaxomicin be used as first line in CDI [10]; however, the majority of patients in our study were hospitalised before this guideline could be implemented. Nevertheless, most patients did not receive the correct treatment choice according to the guidelines $[10,18]$. This indicates the need for hospitals' infection prevention and control teams to organise dedicated seminars on CDI for medical personnel. The knowledge about correct antibiotic prescriptions and antimicrobial resistance is one of the main important threats identified by the World Health Organisation [46]. One study involving 1179 junior doctors found that questions on antimicrobial use were poorly answered, whilst $81 \%$ of participants stated that teaching 
about appropriate antimicrobial use was inadequate during their medical training and $71 \%$ disagreed that they received the right examples from their tutors [47].

Our study shows that CDI therapy was well tolerated, since the percentage of patients whose therapy was altered due to side effects was very small. As it can be seen in Supplementary Materials, almost all patients were treated with the use of well-known conventional drugs. Only one patient was a participant of a cadazolid trial. Cadazolid is a novel quinoxolidinone antibiotic developed for treating CDI, which was safe and well tolerated but did not achieve its primary endpoint of non-inferiority to vancomycin for clinical cure in one of two phase 3 CDI trials [48]. Three patients were treated with the use of intravenous immunoglobulin (IVIG) which sometimes is used in CDI treatment, but reports as to its effectiveness are ambiguous [49,50]. None were treated with Bezlotoxumab, a monoclonal antibody that binds to C. difficile toxin $\mathrm{B}$, which was approved by the FDA in 2016 for prevention of recurrent CDI in patients at high risk of CDI recurrence [51].

Our study has several limitations. It was a retrospective study and some data were unavailable. In addition, there are substantial differences in the numbers of patients included by each centre. However, we did not want to refuse any centre that wished to participate. We were unable to distinguish between cases when CDI was the primary cause of death and when it was not, and there was no ribotyping / sequencing data.

\section{Conclusions}

In our multicentre study, the independent risk factors for mortality at day 90 were older age, inadequate CDI therapy, cachexia, malignancy, Charlson Index, LTC facility care, elevated WBC, elevated CRP, bacteraemia, complications, and cognitive impairment. CDI prevention should be primarily focused on hospitalised elderly people receiving antibiotics, especially fluoroquinolones or $\beta$-lactam / $\beta$-lactamase inhibitors. For this group, we suggest using available preventive measures all the time, instead of, as is presently often done, after CDI diagnosis.

Supplementary Materials: The following are available online at https:/ /www.mdpi.com/2079-638 2/10/3/299/s1 Research data.

Author Contributions: Conceptualization, J.C., M.K. (Marcela Krutova), A.M., N.K., D.A.E., M.P., A.A., and X.N.; Formal analysis, J.S.; Investigation, J.C., M.K. (Marcela Krutova), A.M., N.K., D.A.E., M.P., A.A. and X.N.; Visualisation, J.S.; Writing—original draft, J.C., M.K. (Marcela Krutova), A.M., N.K., D.A.E., M.P., A.A. and X.N.; Writing—review \& editing, J.C., M.K. (Marcela Krutova), A.M., N.K., D.A.E., M.P., A.D., A.A., X.N., H.P., M.W.-B., I.F.-B., B.B., M.K. (Marcin Krzanowski), K.K., M.F., M.M., L.M., P.V., T.G., A.J., S.G.-M., D.W., E.J.K., J.S., G.B. and A.G. All authors have read and agreed to the published version of the manuscript.

Funding: This research did not receive any specific grant from funding agencies in the public, commercial, or not-for-profit sectors.

Institutional Review Board Statement: The study was conducted according to the guidelines of the Declaration of Helsinki (as revised in Brazil 2013). Since it was a retrospective study, based on standard data gathered at the hospitals (data that were sent anonymously and with no identifying personal information), informed consent was not required.

Informed Consent Statement: Informed consent was not required.

Data Availability Statement: Research data are available as Supplementary Materials.

Acknowledgments: We would like to express our appreciation for help in data acquisition to: Martina Barchitta and Claudia La Mastra from Department of Medical and Surgical Sciences and Advanced Technologies "GF Ingrassia", University of Catania, Catania, Italy; Graziella Manciagli, Giuseppe Giammanco, Angela Privitera, and Nunzio Sciacca from ARNAS Garibaldi Nesima Hospital, Catania, Italy.

Conflicts of Interest: The authors declare no conflict of interest. 


\section{References}

1. Elliott, B.; Androga, G.O.; Knight, D.R.; Riley, T.V. Clostridium difficile infection: Evolution, phylogeny and molecular epidemiology. Infect. Genet. Evol. 2017, 49, 1-11. [CrossRef] [PubMed]

2. European Surveillance of Clostridium difficile infections. In Surveillance Protocol Version 2.2; European Centre for Disease Prevention and Control (ECDC): Stockholm, Sweden, 2015. [CrossRef]

3. Magill, S.S.; O'Leary, E.; Janelle, S.J.; Thompson, D.L.; Dumyati, G.; Nadle, J.; Wilson, L.E.; Kainer, M.A.; Lynfield, R.; Greissman, S.; et al. Emerging Infections Program Hospital Prevalence Survey Team. Changes in prevalence of health care-associated infections in U.S. hospitals. N. Engl. J. Med. 2018, 379, 1732-1744. [CrossRef] [PubMed]

4. Lessa, F.C.; Mu, Y.; Bamberg, W.M.; Beldavs, Z.G.; Dumyati, G.K.; Dunn, J.R.; Farley, M.M.; Holzbauer, S.M.; Meek, J.I.; Phipps, E.C.; et al. Burden of Clostridium difficile infection in the United States. N. Engl. J. Med. 2015, 372, 825-834. [CrossRef]

5. Borren, N.Z.; Ghadermarzi, S.; Hutfless, S.; Ananthakrishnan, A.N. The emergence of Clostridium difficile infection in Asia: A systematic review and meta-analysis of incidence and impact. PLoS ONE 2017, 12, e0176797. [CrossRef] [PubMed]

6. He, M.; Miyajima, F.; Roberts, P.; Ellison, L.; Pickard, D.J.; Martin, M.J.; Connor, T.R.; Harris, S.R.; Fairley, D. Emergence and global spread of epidemic healthcare-associated Clostridium difficile. Nat. Genet. 2013, 45, 109-113. [CrossRef] [PubMed]

7. Czepiel, J.; Dróżdż, M.; Pituch, H.; Kuijper, E.J.; Perucki, W.; Mielimonka, A.; Goldman, S.; Wultańska, D.; Garlicki, A.; Biesiada, G. Clostridium difficile infection: Review. Eur. J. Clin. Microbiol. Infect. Dis. 2019, 38, 1211-1221. [CrossRef]

8. Leffler, D.A.; Lamont, J.T. Clostridium difficile infection. N. Engl. J. Med. 2015, 373, 287-288. [CrossRef]

9. Ofori, E.; Ramai, D.; Dhawan, M.; Mustafa, F.; Gasperino, J.; Reddy, M. Community-acquired Clostridium difficile: Epidemiology, ribotype, risk factors, hospital and intensive care unit outcomes, and current and emerging therapies. J. Hosp. Infect. 2018, 99, 436-442. [CrossRef] [PubMed]

10. McDonald, L.C.; Gerding, D.N.; Johnson, S.; Bakken, J.S.; Carroll, K.C.; Coffin, S.E.; Dubberke, E.R.; Garey, K.W.; Gould, C.V.; Kelly, C.; et al. Clinical practice guidelines for Clostridium difficile infection in adults and children: 2017 update by the Infectious Diseases Society of America (IDSA) and Society for Healthcare Epidemiology of America (SHEA). Clin. Infect. Dis. 2018, 66, e1-e48. [CrossRef]

11. Kwon, J.H.; Olsen, M.A.; Dubberke, E.R. The morbidity, mortality, and costs associated with Clostridium difficile infection. Infect. Dis. Clin. N. Am. 2015, 29, 123-134. [CrossRef]

12. Kyne, L.; Hamel, M.B.; Polavaram, R.; Kelly, C.P. Health care costs and mortality associated with nosocomial diarrhea due to Clostridium difficile. Clin. Infect. Dis. 2002, 34, 346-353. [CrossRef] [PubMed]

13. Miller, M.A.; Hyland, M.; Ofner-Agostini, M.; Gourdeau, M.; Ishak, M.; Canadian Hospital Epidemiology Committee. Canadian Nosocomial Infection Surveillance Program. Morbidity, mortality, and healthcare burden of nosocomial Clostridium difficileassociated diarrhea in Canadian hospitals. Infect. Control. Hosp. Epidemiol. 2002, 23, 137-140. [CrossRef]

14. Olson, M.M.; Shanholtzer, C.J.; Lee, J.T., Jr.; Gerding, D.N. Ten years of prospective Clostridium difficile-associated disease surveillance and treatment at the Minneapolis VA Medical Center, 1982-1991. Infect. Control. Hosp. Epidemiol. 1994, 15, 371-381. [CrossRef]

15. Dallal, R.M.; Harbrecht, B.G.; Boujoukas, A.J.; Sirio, C.A.; Farkas, L.M.; Lee, K.K.; Simmons, R.L. Fulminant Clostridium difficile: An underappreciated and increasing cause of death and complications. Ann. Surg. 2002, 235, 363-372. [CrossRef]

16. Vincent, J.L.; Rello, J.; Marshall, J.; Silva, E.; Anzueto, A.; Martin, C.D.; Moreno, R.; Lipman, J.; Gomersall, C.; Sakr, Y.; et al. International study of the prevalence and outcomes of infection in intensive care units. JAMA 2009, 302, 2323-2329. [CrossRef]

17. Sidler, J.A.; Battegay, M.; Tschudin-Sutter, S.; Widmer, A.F.; Weisser, M. Enterococci, Clostridium difficile and ESBL producing bacteria: Epidemiology, clinical impact and prevention in ICU patients. Swiss Med. Wkly. 2014, 144, 14009. [CrossRef] [PubMed]

18. Debast, S.B.; Bauer, M.P.; Kuijper, E.J.; ESCMID. European Society of Clinical Microbiology and Infectious Diseases: Update of the treatment guidance document for Clostridium difficile infection. Clin. Microbiol. Infect. 2014, 20, 1-26. [CrossRef]

19. Krutova, M.; Kinross, P.; Barbut, F.; Hajdu, A.; Wilcox, M.H.; Kuijper, E.J.; Allerberger, F.; Delmée, M.; Van Broeck, J.; VatchevaDobrevska, R.; et al. How to: Surveillance of Clostridium difficile infections. Microbiol. Infect. 2018, 24, 469-475. [CrossRef] [PubMed]

20. Banks, A.; Moore, E.K.; Bishop, J.; Coia, J.E.; Brown, D.; Mather, H.; Wiuff, C. Trends in mortality following Clostridium difficile infection in Scotland, 2010-2016: A retrospective cohort and case control study. J. Hosp. Infect. 2018, 100, $133-141$. [CrossRef] [PubMed]

21. Chintanaboina, J.; Navabi, S.; Suchniak-Mussari, K.; Stern, B.; Bedi, S.; Lehman, E.B.; Tinsley, A. Predictors of 30-day mortality in hospitalized patients with Clostridium difficile infection. S. Med. J. 2017, 110, 546-549. [CrossRef]

22. Abou Chakra, C.N.; Pepin, J.; Sirard, S.; Valiquette, L. Risk factors for recurrence, complications and mortality in Clostridium difficile infection: A systematic review. PLoS ONE 2014, 9, e98400. [CrossRef] [PubMed]

23. Johnson, S. Recurrent Clostridium difficile infection: A review of risk factors, treatments, and outcomes. J. Infect. 2009, 58, 403-410. [CrossRef]

24. Morrison, R.H.; Hall, N.S.; Said, M.; Rice, T.; Groff, H.; Brodine, S.K.; Slymen, D.; Lederman, E.R. Risk factors associated with complications and mortality in patients with Clostridium difficile infection. Clin. Infect. Dis. 2011, 53, 1173-1178. [CrossRef]

25. Takahashi, M.; Mori, N.; Bito, S. Multi-institution case-control and cohort study of risk factors for the development and mortality of Clostridium difficile infections in Japan. BMJ Open 2014, 4, e005665. [CrossRef]

26. Larentis, D.Z.; Rosa, R.G.; Dos Santos, R.P.; Goldani, L.Z. Outcomes and risk factors associated with Clostridium difficile diarrhea in hospitalized adult patients. Gastroenterol. Res. Pract. 2015, 2015, 346341. [CrossRef] [PubMed] 
27. Appaneal, H.J.; Caffrey, A.R.; Beganovic, M.; Avramovic, S.; LaPlante, K.L. Predictors of mortality among a national cohort of veterans with recurrent Clostridium difficile infection. Open Forum Infect. Dis. 2018, 5, ofy175. [CrossRef] [PubMed]

28. Cozar-Llisto, A.; Ramos-Martinez, A.; Cobo, J. Clostridium difficile infection in special high-risk populations. Infect. Dis. Ther. 2016, 5, 253-269. [CrossRef] [PubMed]

29. Anand, A.; Glatt, A.E. Clostridium difficile infection associated with antineoplastic chemotherapy: A review. Clin. Infect. Dis. 1993, 17, 109-113. [CrossRef] [PubMed]

30. Loo, V.G.; Bourgault, A.M.; Poirier, L.; Lamothe, F.; Michaud, S.; Turgeon, N.; Toye, B.; Beaudoin, A.; Frost, E.H.; Gilca, R.; et al. Host and pathogen factors for Clostridium difficile infection and colonization. N. Engl. J. Med. 2011, 365, 1693-1703. [CrossRef] [PubMed]

31. Bishop, K.D.; Castillo, J.J. Risk factors associated with Clostridium difficile infection in adult oncology patients with a history of recent hospitalization for febrile neutropenia. Leuk. Lymphoma 2012, 53, 1617-1619. [CrossRef]

32. Delgado, A.; Reveles, I.A.; Cabello, F.T.; Reveles, K.R. Poorer outcomes among cancer patients diagnosed with Clostridium difficile infections in United States community hospitals. BMC Infect. Dis. 2017, 17, 448. [CrossRef]

33. Trifan, A.; Stanciu, C.; Stoica, O.; Girleanu, I.; Cojocariu, C. Impact of Clostridium difficile infection on inflammatory bowel disease outcome: A review. World J. Gastroenterol. 2014, 20, 11736-11742. [CrossRef] [PubMed]

34. Pant, C.; Deshpande, A.; Anderson, M.P.; Sferra, T.J. Clostridium difficile infection is associated with poor outcomes in end-stage renal disease. J. Investig. Med. 2012, 60, 529-532. [CrossRef]

35. Thongprayoon, C.; Cheungpasitporn, W.; Phatharacharukul, P.; Edmonds, P.J.; Kaewpoowat, Q.; Mahaparn, P.; Bruminhent, J.; Erickson, S.B. Chronic kidney disease and end-stage renal disease are risk factors for poor outcomes of Clostridium difficile infection: A systematic review and meta-analysis. Int. J. Clin. Pract. 2015, 69, 998-1006. [CrossRef] [PubMed]

36. López-de-Andrés, A.; Esteban-Vasallo, M.D.; de Miguel-Díez, J.; Hernández-Barrera, V.; de Miguel-Yanes, J.M.; Méndez-Bailón, M.; Jiménez-García, R. Incidence and in-hospital outcomes of Clostridium difficile infection among type 2 diabetes patients in Spain. Int. J. Clin. Pract. 2018, 72, e13251. [CrossRef]

37. Qu, H.Q.; Jiang, Z.D. Clostridium difficile infection in diabetes. Diabetes Res. Clin. Pract. 2014, 105, 285-294. [CrossRef]

38. Nathanson, B.H.; Higgins, T.L.; McGee, W.T. The dangers of extreme body mass index values in patients with Clostridium difficile. Infection 2017, 45, 787-793. [CrossRef] [PubMed]

39. Mansoor, M.S.; Feuerstadt, P. Underweight patients with C. difficile infection (CDI) are at higher risk of poor outcome than normal, overweight and obese patients. Gastroenterology 2015, 148, S484. [CrossRef]

40. Lawes, T.; Lopez-Lozano, J.M.; Nebot, C.A.; Macartney, G.; Subbarao-Sharma, R.; Wares, K.D.; Sinclair, C.; Gould, I.M. Effect of a national 4C antibiotic stewardship intervention on the clinical and molecular epidemiology of Clostridium difficile infections in a region of Scotland: A non-linear time-series analysis. Lancet Infect. Dis. 2017, 17, 194-206. [CrossRef]

41. Bhangu, S.; Bhangu, A.; Nightingale, P.; Michael, A. Mortality and risk stratification in patients with Clostridium difficile-associated diarrhoea. Colorectal. Dis. 2010, 12, 241-246. [CrossRef]

42. Pant, C.; Madonia, P.; Minocha, A.; Manas, K.; Jordan, P.; Bass, P. Laboratory markers as predictors of mortality in patients with Clostridium difficile infection. J. Invest. Med. 2010, 58, 43-45. [CrossRef]

43. Gujja, D.; Friedenberg, F.K. Predictors of serious complications due to Clostridium difficile infection. Aliment. Pharmacol. Ther. 2009, 29, 635-642. [CrossRef]

44. Czepiel, J.; Kędzierska, J.; Biesiada, G.; Birczyńska, M.; Perucki, W.; Nowak, P.; Garlicki, A. Epidemiology of Clostridium difficile infection: Results of a hospital-based study in Krakow, Poland. Epidemiol. Infect. 2015, 143, 3235-3243. [CrossRef]

45. Paláu-Dávila, L.; Lara-Medrano, R.; Negreros-Osuna, A.A.; Salinas-Chapa, M.; Garza-González, E.; Gutierrez-Delgado, E.M.; Camacho-Ortiz, A. Efficacy of computed tomography for the prediction of colectomy and mortality in patients with Clostridium difficile infection. Ann. Med. Surg. (Lond.) 2016, 12, 101-105. [CrossRef]

46. World Health Organization (WHO). Ten Threats to Global Health in 2019; WHO: Geneva, Switzerland, 2019. Available online: https://www.who.int/news-room/spotlight/ten-threats-to-global-health-in-2019 (accessed on 1 May 2019).

47. Di Gennaro, F.; Marotta, C.; Amicone, M.; Bavaro, D.F.; Bernaudo, F.; Frisicale, E.M.; Kurotschka, P.K.; Mazzari, A.; Veronese, N.; Murri, R.; et al. Italian young doctors' knowledge, attitudes and practices on antibiotic use and resistance: A national cross-sectional survey. J. Glob. Antimicrob. Resist. 2020, 23, 167-173. [CrossRef]

48. Gerding, D.N.; Cornely, O.A.; Grill, S.; Kracker, H.; Marrast, A.C.; Nord, C.E.; Talbot, G.H.; Buitrago, M.; Diaconescu, I.G.; de Oliveira, C.M.; et al. Cadazolid for the treatment of Clostridium difficile infection: Results of two double-blind, placebo-controlled, non-inferiority, randomised phase 3 trials. Lancet Infect. Dis. 2019, 19, 265-274. [CrossRef]

49. Abougergi, M.A.; Broor, A.; Cui, W.; Jaar, B.G. Intravenous immunoglobulin for the treatment of severe Clostridium difficile colitis: An observational study and review of the literature. J. Hosp. Med. 2010, 5, E1-E9. [CrossRef] [PubMed]

50. Shah, N.; Shaaban, H.; Spira, R.; Slim, J.; Boghossian, J. Intravenous immunoglobulin in the treatment of severe Clostridium difficile colitis. J. Glob. Infect. Dis. 2014, 6, 82-85. [PubMed]

51. Wilcox, M.H.; Gerding, D.N.; Poxton, I.R.; Kelly, C.; Nathan, R.; Birch, T.; Cornely, O.A.; Rahav, G.; Bouza, E.; Lee, C.; et al. Bezlotoxumab for prevention of recurrent Clostridium difficile infection. N. Engl. J. Med. 2017, 376, 305-317. [CrossRef] [PubMed] 